\title{
Research on Moral Judgment Competency of College Students in Mainland China with DIT-2
}

\author{
Qian Zhang \\ (Guangdong University of Foreign Studies, gwzhangqian@126.com) \\ Stephen J. Thoma \\ (University of Alabama, sthoma@bamaed.ua.edu)
}

\section{Introduction}

An important contribution to measurement in moral judgment research is James Rest's Defining Issues Test (DIT), which was constructed and validated in the 1970s (Rest 1975, 1976, 1979a, 1979b; Rest, Cooper, Coder, Masanz, \& Anderson 1974) and developed into DIT-2 in 1990s (Rest \& Narvaez 1998; Rest, Thoma, Narvaez \& Bebeau 1997). The test was constructed on the basis of Kohlberg's developmental theory, but different from it. Rest and his research team realized that the development of an individual's moral reasoning is not confined to one particular stage at a time, as claimed by Kohlberg. Instead, he has all stages of reasoning at a time, and the only difference from one another is the distribution of those stages at different times.

Based on the above notion, they proposed three developmentally ordered schemas. The first schema is Personal Interests. People in this schema care about the gains and losses of themselves and of the people with kinship or intimate relationship. They make moral decision based on the consideration of exchanging favor for favor, and on the intentions to maintain good relationships and seek approvals. The second schema is Maintaining Norms, which concerns "the formal structure of society as defined by institutions, rules and roles" (Rest et al. 1999), such as whether one should cooperate with non-kinship others, and how, based on the current laws, regulations, and norms, to develop cooperation in social scope, etc. Individuals adopting this schema take laws, order and regulations as the sole unchanged foundation of the structure of society, as well as the organizing vehicle for moral decision making through partial reciprocity. The third schema, Postconventional schema, is defined as "justifications for an act are made by arguing that the act would respect other people, that the act serves shareable social goals, that the act optimizes the welfare of all participants" (Rest et al. 2009). People in this schema take moral criteria (e.g., shareable ideals) over social conventions (e.g., laws and regulations), full reciprocity (e.g., the benefits of all human beings) over partial reciprocity (e.g., the benefits of a group of people), in moral decision-making. They are aware that the existing 
laws and regulations can be biased and alterable, benefiting a certain group of people at the expense of another. Therefore, when the existing laws and legal systems are against sharable ideals, people have the right to change them based on moral criteria.

The scoring system of DIT-2 comes from the participant's score in the above three schemas after rating and ranking of the five dilemma stories in the test. That is, the score in Personal Interest schema (thereafter PI score), the score in Maintaining Norms schema (thereafter MN score), the score in Postconventional schema (thereafter P score). N2 score is a composite score of the participant's moral judgment competence which is calculated through the resultant weighted algorithm from both rating and ranking data.

Even though DIT-2 has been proved a well-validated measurement tool in America and other Western cultures (Davison et al. 1978; Martin et al. 1977; Rest 1979b), researches using DIT-2 in Chinese cultural setting are still limited.

Evidence shows that after DIT was introduced into mainland China in 1980s (Chen 1988; Gu \& Li 1997), studies had been mostly focused on the theoretical research (Chen 1988; Gu \& Li 1997; Yang \& Wu 2004; Yang 2006). Xiujuan Sun was the first scholar to conduct empirical study with DIT-2 in mainland China. She tested DIT-2 reliability and validity in Chinese settings in her master thesis (Sun 2007). Her research proved that DIT-2 was applicable in non-western cultural settings. After her studies, there emerged some researches using DIT-2 to explore moral judgment competence of government officials (Zhao 2007), relationship between moral judgment and ethical audit (Li 2014), relationship between moral cognition development and ethical decision-making among accountants (Yang \& Zeng 2014). Despite the flourishing research using DIT-2 in China, there is no scholar so far taking college students as participants to explore the general characteristics of their moral judgment competence, and to explore what demographic factors may influence them.

The purpose of this study was (1) to use DIT-2 to examine the moral judgment competence of college students in mainland China, and (2) to study whether gender, education level, major, academic performance and one-child family have significant effect on college students' moral judgment competence.

\section{Method}

\subsection{Sample}

Students ranging from first to fourth year of undergraduate programs in a southern university in Mainland China were invited to take DIT-2 test in the class of Moral Psychology. The measure was presented in a group setting using the paper and pencil version following standard procedures (DIT-2 manual). Participants were offered one extra credit in that class for their participation. 
The sample consisted of 831 students, of which 811 supplied valid data across measures by the Center for the Study of Ethical Development in University of Alabama. In this sample, there were 241 freshmen, 199 sophomore, 221 junior and 150 seniors. Age ranged very little in the sample because the undergraduate student population is quite traditional. Although both sexes were included in the sample, more women $(\mathrm{N}=527,65.0 \%)$ than men $(\mathrm{N}=284,35.0 \%)$ participated in the study. The students in question were studying

a range of academic disciplines including: Education $(\mathrm{N}=100,12.3 \%)$; Humanity $(\mathrm{N}=138,17.0 \%)$; Language $(\mathrm{N}=175,21.6 \%)$; Accounting $(\mathrm{N}=105$, 12.9\%); Natural Sciences (N=96, 11.8\%); Informatics and Electronics $(\mathrm{N}=103$, $12.7 \%)$; and engineering studies $(\mathrm{N}=84,10.3 \%)$. Based on the information available, ages at baseline ranged from 16 to 23 years $(M=19.68, S D=1.40)$ (see Table 1).

\begin{tabular}{ll}
\hline Program & Number of participants (\%) \\
\hline Education & $100(12.3 \%)$ \\
Humanity & $138(17.0 \%)$ \\
Language & $175(21.6 \%)$ \\
accounting & $105(12.7 \%)$ \\
natural sciences & $96(11.8 \%)$ \\
informatics and electronics & $103(12.7 \%)$ \\
engineering studies & $84(10.3 \%)$ \\
\hline
\end{tabular}

Table 1. Course of study of participants

\subsection{Instrument}

To explore the moral judgment competence of Chinese participants, and the related influencing factors, the instruments used in this research are: (1) Chinese version of DIT-2 test; (2) demographic items which include gender, education level, major, academic performance and one-child policy.

The English version was translated into Chinese with reference to the existing Chinese versions (Sun 2005). Sun's Chinese version of DIT-2 was proved to be adequate in reliability $(\alpha=0.72)$ and validity. The translated Chinese version was then back-translated by two Chinese scholars who majored in English and now are teaching in American colleges into English to check the accuracy of translation. 


\section{Results and Discussion}

1. Participants in the sample show a unique $U$ pattern in schema distribution. The means and standard deviations of the DIT-2 indices (PI, MN, $\mathrm{P}, \mathrm{N} 2$ ) in the current sample are presented in Table 2. It illustrates that participants in this sample scored high in both Personal Interest schema and Postconventional schema, but low in Maintaining Norms schema.

\begin{tabular}{lll}
\hline & Mean & Standard Deviation \\
\hline Postconventional & 33.5 & 11.9 \\
Personal Interest & 29.2 & 10.8 \\
Maintaining Norms & 27.9 & 10.5 \\
N2 & 32.6 & 10.6 \\
\hline
\end{tabular}

Table 2. Means and standard deviations of the DIT-2 indices in Mainland Chinese sample

This pattern is different from the developmental pattern of moral judgment competence tested by DIT in general. Since DIT conceptualizes moral development as shifting distribution of the schemas when primitive ways of thinking are gradually replaced by advanced ways of thinking, it is naturally the case that the progression in higher schema means the degression in lower schema. That is how N2 score is calculated which has been stated in detail earlier in this paper.

To show it more clearly, a group of college students from America is taken for comparison with this sample. The data of the American participants is randomly taken from the data of the mega sample of the American participants from 2011 to 2014, which is provided by the Center for the Study of Ethical Development in University of Alabama. The American sample has the same size $(\mathrm{N}=811)$, with the same amount of participants of gender (female $\mathrm{N}=537,65.5 \%$; male $\mathrm{N}=284,34.5 \%$ ), divided the same by education level with the Chinese sample.

Table 3 presents the means and standard deviations of the DIT-2 indices with the American sample. As can be seen clearly, while there shows a consistent developmental trend from Personal Interest schema to Postconventional schema via Maintaining Norms schema in American participants, the Chinese participants show a unique $U$ pattern, that is, high in Personal Interest schema and Postconventional schema but low in Maintaining Norms schema. 


\begin{tabular}{lll}
\hline & Mean & Standard Deviation \\
\hline Postconventional & 34.2 & 15.5 \\
Personal Interest & 27.1 & 12.7 \\
Maintaining Norms & 33.6 & 13.7 \\
N2 & 33.3 & 14.9 \\
\hline
\end{tabular}

Table 3. Means and standard deviations of the DIT-2 indices in American samples

The findings are consistent with some researches which claimed that the Chinese tend to have pervasive and persistent emphasis on affection and conformity (Ma 1988). However, it is in conflict with some other researches which suggest that Chinese participants all focused more on the conventional level than on the postconventional (Lin \& Ho 2009), and Chinese participants place greater emphasis on helpfulness and obligation to kin (Chow \& Ding 2002).

There are possibly two major reasons for the unique developmental pattern of the Chinese participants in this sample. Firstly, economic reformation changes people's values. Since the government adopted the "reforming and opening up" policy at the end of 1970s, mainland China has experienced unprecedentedly innovative changes in economy, politics and culture. Different from the planned economy in which model all the resources and products were completely regulated and distributed by the government, the market economy requires that all the sales have to be manipulated by the market. The change in economic style promotes people's personal initiative, self motivation and creativity. In accordance with the economic change, there have been predominant changes in both politics and culture. A highly centralized state which enforced administrative order and personal authority of the leader started to give way to a more democratic country which respects the equal role and legal interests of the individual in social context. In that situation, moral education in schools has also taken a transfer from a complete rejection of obtaining personal interests to reasonably accepting it.

The influence of traditional Chinese culture. Firstly, China has a 5000year history of culture, which is greatly affected by Confucian ethics. In Confucian ethics, "family" and "country" are closely associated, and its essence is to educate an individual to love the country by cultivating himself and loving his family first. It believes that "self-cultivation of the individual serves as the basis for putting the family in order, which in turn is the basis for governing the state and pacifying the world" (Ma \& Liu 2017).

With that said, traditional Chinese culture emphasizes the family relationship (kinship). As the old saying goes, "Expand the respect for the elderly in one's family to that of other families, expand the love for the children in one's family to that of other families, then it is easy to govern a 
state" (Mencius, King Hui of Liang), family is the basis as well as the starting point of all social relations. The tight family relationship is also reflected in the Five Cardinal Relationships, which is used to manipulate the personal relationships in traditional Chinese culture. It emphasized the harmonious relationship between "Emperor and subjects, father and son, husband and wife, brothers, and friends." Even in modern China, Five Cardinal Relationship is still playing an undeniably important role. According to a survey recently conducted all over China, the new Five Cardinal Relationships, a revised version of the old one as a result of modernization of China, still put the family relationships on the top three, i.e. father and son, husband and wife, brothers and sisters, colleagues or classmates, friends (Fan 2015, 12). Cross-cultural studies also found that Chinese participants showed a stronger orientation to perform affective and altruistic acts to first kin, close relatives and best friends than their English counterparts (Ma 1989; Cheung \& King 2004).

Secondly, traditional Chinese culture also takes the moral standards like benevolence, righteousness, propriety, sincerity, etc. as the criteria to discipline one's behaviors. "Being righteous is the foremost thing in the world"

(Mo-tse Scripture, "The determined scholar and the man of virtue will not seek to live at the expense of injuring their virtue. They will even sacrifice their lives to preserve their virtue complete". The Analects of Confucius, "It is worth sacrificing oneself for justice" (Mencius), "Riches and honors acquired by unrighteousness, are to me as useless as a floating cloud" (The Analects of Confucius), "Righteousness should always be considered than benefits". Those scriptures have been deeply rooted in Chinese people's mind and strictly followed in their daily life.

With what is stated above, due to the influence of both traditional and modern culture in China, it is understandable that the participants in the current research would score high both in Personal Interest schema and Postconventional schema, which seems to be two conflicting forces.

\section{Students}

Influencing Factors on Moral Judgment Competence of College

Moral judgment competence of college students is compared by independent $t$ test or one-way ANOVA as follows:

(1) Moral judgment competence of college students is significantly different by gender.

In the current research, results of independent $t$ test show that males and females are significantly different in moral judgment competence $(\mathrm{t}=-$ 5.156, $\mathrm{df}=562.685, \mathrm{p}<.001$ ). Table 4 is a comparison in means and standard deviation of the $\mathrm{P}$ and $\mathrm{N} 2$ index. Females' moral judgment competenceis significantly higher than males. 


\begin{tabular}{llllll}
\hline & Male & & \multicolumn{3}{l}{ Female } \\
\hline Mean & SD & N & Mean & SD & $\mathrm{N}$ \\
33.48 & 11.5 & 284 & 37.82 & 11.23 & 527 \\
\hline
\end{tabular}

Table 4. Means and standard deviation for the N2 index by gender

(2) Moral judgment competence of college students is significantly different by majors.

Researchers (e.g. King and Mayhew, 2004) studied the effect of the type of the university on moral judgment. The result showed that students from Liberal Arts College scored higher ${ }^{1}$.

Table 5 shows that college students in different majors are significantly different in moral judgment competence in $\mathrm{N} 2(\mathrm{~F}=12.920, \mathrm{p}<0.001)$. The overall testing $\mathrm{F}$ is $3.464(\mathrm{p}=0.032<0.05), 1.936 \quad(\mathrm{p}=0.145>0.05)$, and $11.588 \quad(\mathrm{p}<0.001)$ for Personal Interest schema, Maintaining Norms schema and Postconventional schema respectively. The Post-hoc tests with Scheffe method show that students majoring in Arts have significantly higher moral judgment competence than others.

\begin{tabular}{|c|c|c|c|c|c|c|c|}
\hline & & Sum of Square & $\overline{\text { Df. }}$ & Mean Square & $\bar{F}$ & Sig. & Post-hoc Scheffe \\
\hline \multirow{3}{*}{$\mathrm{P}$} & $\begin{array}{l}\text { Between } \\
\text { Group }\end{array}$ & 3863.229 & 2 & 1931.615 & 11.588 & 0.000 & $\begin{array}{l}\text { Arts>other } \\
\text { majors }\end{array}$ \\
\hline & Within Group & 133185.616 & 809 & 166.69 & & & \\
\hline & Sum & 137048.846 & 811 & & & & \\
\hline \multirow{3}{*}{ PI } & $\begin{array}{l}\text { Between } \\
\text { Group }\end{array}$ & 962.131 & 2 & 481.065 & 3.464 & 0.032 & $\begin{array}{l}\text { Arts }<\text { other } \\
\text { majors }\end{array}$ \\
\hline & Within Group & 110971.183 & 809 & 138.888 & & & \\
\hline & Sum & 111933.314 & 811 & & & & \\
\hline \multirow{3}{*}{$\mathrm{MN}$} & $\begin{array}{l}\text { Between } \\
\text { Group }\end{array}$ & 495.153 & 2 & 247.577 & 1.936 & 0.145 & $\begin{array}{l}\text { Arts }>\text { other } \\
\text { majors }\end{array}$ \\
\hline & Within Group & 102201.688 & 809 & 127.912 & & & \\
\hline & Sum & 102696.841 & 811 & & & & \\
\hline \multirow{3}{*}{$\mathrm{N} 2$} & $\begin{array}{l}\text { Between } \\
\text { Group }\end{array}$ & 3316.37 & 2 & 1658.185 & 12.92 & 0.000 & \\
\hline & Within Group & 102418.561 & 809 & 128.344 & & & $\begin{array}{l}\text { Arts }>\text { other } \\
\text { majors }\end{array}$ \\
\hline & Sum & 105734.931 & 811 & & & & \\
\hline
\end{tabular}

Table 5. Correlation of major with DIT-2 indices

${ }^{1}$ In mainland China, there is no such Liberal Arts College as in America, but the majors in the sample can be categorized into three types by the courses they learn, that is, Arts, Science, and Technology. Majors like Humanity, Language and Education belong to Arts; Accounting, Natural Sciences belong to Science; Informatics and Electronics belong to Technology. Result shows that students majoring in Arts score higher in moral judgment than other majors 
This finding may be accounted for by the influence of the courses and the teaching methods of different majors. The courses which intend to promote students' thinking are helpful to promote their moral reasoning. The investigation revealed that courses on ethics, social diversity and social justice have some positive influence in promoting students' moral reasoning. Dilemma discussions, group discussions and deep reflections also help students to improve their moral reasoning (King \& Mayhew 2004). Compared with students from Science and Technology, students majoring in Arts have more sociological courses. In this sample, of the 154 credits, credits on sociological studies range from 60 to 78 for students majoring in Humanity, Language and Education. For students majoring in Science, the credits for sociology are 35 and 41 for Natural Science and Accounting respectively. For students majoring in Technology, the credits are only 17 for Informatics and 19 for Electronics.

(3) Moral judgment competence of college students is not significantly different by education levels.

It was proposed by the developers of the DIT test that there is a significant relationship between moral judgment competence and education level (Bebeau \& Thoma 2003). Studies have shown that $30 \%$ to $50 \%$ of the variance of DIT scores is attributable to the level of education (Rest, et al. 1999). However, the result of a one-way ANOVA conducted on the sample in the current research showed an F of 0.883 and a p of 0.449 for the effect of educational level on N2 score. These results do not meet the $0.05 \alpha$-test for significance.

\begin{tabular}{|c|c|c|c|c|c|c|c|}
\hline & & Sum of Square & Df. & Mean Square & $\mathrm{F}$ & Sig. & Post-hoc Scheffe \\
\hline \multirow{3}{*}{$P$} & $\begin{array}{l}\text { Between } \\
\text { Group }\end{array}$ & 3863.229 & 2 & 1931.615 & 11.588 & 0.000 & $\begin{array}{l}\text { Arts>other } \\
\text { majors }\end{array}$ \\
\hline & Within Group & 133185.616 & 809 & 166.69 & & & \\
\hline & Sum & 137048.846 & 811 & & & & \\
\hline \multirow{3}{*}{ PI } & $\begin{array}{l}\text { Between } \\
\text { Group }\end{array}$ & 962.131 & 2 & 481.065 & 3.464 & 0.032 & $\begin{array}{l}\text { Arts }<\text { other } \\
\text { majors }\end{array}$ \\
\hline & Within Group & 110971.183 & 809 & 138.888 & & & \\
\hline & Sum & 111933.314 & 811 & & & & \\
\hline \multirow{3}{*}{ MN } & $\begin{array}{l}\text { Between } \\
\text { Group }\end{array}$ & 495.153 & 2 & 247.577 & 1.936 & 0.145 & $\begin{array}{l}\text { Arts }>\text { other } \\
\text { majors }\end{array}$ \\
\hline & Within Group & 102201.688 & 809 & 127.912 & & & \\
\hline & Sum & 102696.841 & 811 & & & & \\
\hline \multirow{3}{*}{$\mathrm{N} 2$} & $\begin{array}{l}\text { Between } \\
\text { Group }\end{array}$ & 3316.37 & 2 & 1658.185 & 12.92 & 0.000 & $\begin{array}{l}\text { Arts }>\text { other } \\
\text { majors }\end{array}$ \\
\hline & Within Group & 102418.561 & 809 & 128.344 & & & \\
\hline & Sum & 105734.931 & 811 & & & & \\
\hline
\end{tabular}


The result may be related to the contents and teaching methods of moral education in China. It has been long and widely criticized by educators that the moral education in China is focusing on conveying the knowledge about morality instead of acquiring moral cognition, focusing on learning moral norms instead of improving moral competence, focusing on learning from moral exemplars instead of cultivating moral consciousness (Liu 1995; $\mathrm{Wu} 2000)$.

Some educators criticized the old-fashioned ways in moral education. "Moral education can only achieve the effect by arousing the empathy of the learners, instead of reading the cold rules in the textbook" (Zhu 2000) "the current teaching methods brought about disjunctions between educational theory and practice" (Li, Monica \& Yang 2004). Despite the heated criticism, the reforming in moral education in China is still not satisfactory. The major reason is that the present moral education in China since 1949 is actually socalled "large moral education" (Tan 2003), which includes political education, ideological education, values education, civic education and even includes mental education, physical training and labor education and so on. Strictly speaking, the contemporary China has no special curriculum of "moral education" in the sense of Western understanding. The management and implementation of moral education in China has been facilitated by whatever is conducive to political purposes, neglecting the development of the truly personal and creative mind (Li, Monica \& Yang 2004). In that situation, moral education becomes a serving tool of politics and ideology, straying away from the real meaning of moral education. Teachers distill a certain set of moral values which are consistent with political requirements and ideology into the students. Students trained in this educational system are lack of independent learning, autonomous personality and critical thoughts. Therefore, it is urgent to advocate a reforming in contents and teaching methods in moral education in mainland China. Political and ideological education need to be excluded from the scope of moral education, and educators should organize dilemma discussions to stimulate the conflicts in students' mind and encourage different opinions to develop students' moral judgment competence.

(4) Moral judgment competence of college students is not significantly different by academic performance.

There is an extensive body of research which proves the association between intelligence and academic achievement, although there may be different ideas in the degree of association (Brody 2000; Deary et al. 2007; Jensen 1980; Kuncel et al. 2001; Soares et al. 2015; Zeidner \& Matthews 2000). In this sample, the participants' academic performance was represented by the average score of GPA in academic years. A one-way ANOVA was conducted on the participants, which showed an F of 0.800 and a p of 0.780 for the effect of academic performance on N2 score. These results do not meet the $0.05 \alpha$ - 
test for significance. Therefore, it is revealed that there is no significant correlation between academic performance and moral judgment competence.

\begin{tabular}{lllllll}
\hline & & Sum of Square & Df. & Mean Square & F & Sig. \\
\hline \multirow{4}{*}{ P } & Between Group & 27372.069 & 778 & 153.776 & 0.8 & 0.78 \\
& Within Group & 3842.502 & 20 & 192.125 & & \\
& Sum & 31214.571 & 798 & & & \\
PI & Between Group & 28498.693 & 778 & 160.105 & 1.23 & 0.304 \\
& Within Group & 2603.167 & 20 & 130.158 & & \\
& Sum & 31101.859 & 798 & & & \\
MN & Between Group & 23553.53 & 778 & 132.323 & 1.18 & 0.347 \\
& Within Group & 2242.5 & 20 & 112.125 & & \\
& Sum & 25796.03 & 798 & & & \\
N2 & Between Group & 30542.883 & 778 & 171.589 & 0.763 & 0.823 \\
& Within Group & 4497.125 & 20 & 224.856 & & \\
\hline
\end{tabular}

Table 7. Correlation of academic performance with DIT-2 indices

(5) Moral judgment competence of college students is not significantly different by family type.

Since 1989 China has adopted one-child policy to control the very large population, which imposed great effect on the traditional family structure. The only child is regarded as the "Little Emperor" and spoiled by parents and grandparents. This policy has been long criticized for forming the negative personalities of the child, such as selfishness, self-centeredness, arrogance, lack of responsibility and behaviorable problems, etc. (Qi \& Tang 2004). They are called "Spoiled Generation".

A one-way ANOVA was conducted on the participants, which showed an F of 2.650 and a p of 0.071 for the effect of family type on N2 score. The result revealed that in this sample, whether the participant is the only child in the family or he has siblings has no effect on his moral judgment competence.

The result is quite promising since it is not supporting people's negative impression against the only-child generation. It may give people a new perspective to look at this generation.

\section{Conclusion}

This study explores the general characteristics of college students in modern setting in mainland China, which shows a different pattern from the Western participants by scoring high in Personal Interest schema and Postconventional schema, but low in Maintaining Norms schema. It also tests the correlations of $\mathrm{N} 2$ with gender, education level, major, academic performance, and one-child policy. The result shows that gender and major have significant effect on college students' moral judgment competence in 
mainland China, while education level, academic performance and one-child family have no significant effect on their moral judgment competence.

\section{References}

A record number of Chinese students abroad in 2015 but growth is slowing. 2016 (April 6). Available online at: http://monitor.icef.com/2016/04/a-record-number-of-chinesestudents-abroad-in-2015-but-growth-is-slowing/ (accessed on July 17, 2017)

Bebeau M. J. \& Thoma S. J. 2003. Guide for DIT-2. Tuscaloosa, AL: Center for the Study of Ethical Development.

Biggs D. A. \& Barnett R. 1981. "Moral Judgment Development of College Students." Research in Higher Education 14 (2):91-102.

Brody N. 2000. "History of Theories and Measurements of Intelligence," in R. J. Sternberg (Ed.), Handbook of intelligence. New York: Cambridge University Press (16-33).

Chen,X. 1988. "Daode Pandun de Queding Wenting Ceyan Jiqi Yingyong" [Defining Issues Test and Its Application]. Xinli Kexue Tongxun [Psychology Science Correspondence] 3:19-24.

Chen X. \& Chiu C. Y. 2010. „Rural-Urban Differences in Generation of Chinese and Western Exemplary Persons: The Case of China." Asian Journal of Social Psychology 13 (1):9-18.

Cheung T. S. \& King A. Y. 2004. "Righteousness and Profitableness: The Moral Choices of Contemporary Confucian Entrepreneurs." Journal of Business Ethics 54 (3):245-60.

Chou I. H.-S. \& Ding D. Z. Q. 2002. "Moral Judgment and Conflict Handling Styles Among Chinese in Hong Kong and PRC." Journal of Management Development 21(9):666-79.

Colby A. \& Kohlberg L. 1987. The Measurement of Moral Judgment: Vol. 1. Theoretical Foundations and Research Validation. Cambridge, UK: Cambridge University Press.

Davison M. L., Robbins D., \& Swanson D. 1978. "Stage Structure in Objective Moral Judgments." Developmental Psychology 14:137-46.

Deary I. J., Strand S., Smith P., \& Fernandes C. 2007. "Intelligence and Educational Achievement." Intelligence 35:13-21.

Endicott L., Bock T., \& Narvaez D. 2003. "Moral Reasoning, Intercultural Development and Multicultural Experiences: Relations and Cognitive Underpinnings." International Journal of Intercultural Relations 27 (4):403-19. 
Fan H. 2015. "Lunli Daode Xiandai Zhuanxing de Eenhua Guiji Jiqi Jingshen Tuxiang" [Modern Transformation of Ethics and Morality in China and Its Spiritual Image]. Zhexue Yanjiu [Philosophical Research] 97(6):10613.

Gu H. \& Li B. 1997. "Shanghai Diqu Qingshaonian Daode Panduan Nengli Ceyan de Bianzhi ji Changmo Zhiding" [Constructing the Chinese Moral Judgment Competence Rating Scale for 12-17-year-old School Children]. Xinli Kexue [Journal of Psychological Science] 20:197-201.

Hamilton M. 1991. "The Effects of a Deliberate Psychological Education Program on the Moral Reasoning, Identity Formation, and Achievement Motivation Among Gifted Adolescents." Unpublished doctorate dissertation, North Carolina State University.

Ikujiro N. 1994. "A Dynamic Theory of Organizational Knowledge Creation." Organization Science 5 (1):14-37.

Janos B. \& Robinson N. 1983. "Psychological Development in Intellectually Gifted Children," in F. Horowitz \& M. O'Brien (Eds.), The Gifted and Talented: Developmental Perspectives. Washington D.C.: American Psychological Association (149-95).

Jensen A. R. 1980. "Uses of Sibling Data in Educational and Psychological Research." American Educational Research Journal 17:153-70.

Keen C. 1990. "Effects of a Public Issues Program on Adolescents' Moral and Intellectual Development," in J. Kendall \& Associates (Eds.), Combining Service and Learning: A Resource Book for Community and Public Service, 1. Washington D.C.: National Society for Internships and Experimental Education (393-404).

King P. M. \& Mayhew M. J. 2004. "Theory and Research on the Development of Moral Reasoning Among College Students," in J. C. Smart (Ed.), Higher Education: Handbook of Theory and Research. Netherlands: Kluwer Academic Publishers (375-440).

Kohlberg L. 1976. "Moral Stages and Moralization: The Cognitive Developmental Approach," in T. Lickona (Ed.), Moral Development and Behavior. New York: Holt, Rinehart \& Winston (31-53).

Kohlberg L. 1979. Foreword to J. R. Rest (Ed.), Development in Judging Moral Issues. Minneapolis: University of Minnesota Press.

Kohlberg L. \& Turiel E. 1971. "Moral Development and Moral Education," in L. Kohlberg (Ed.), Collected Papers on Moral Development and Moral Education (410-65).

Kolloff P. \& Stevenson D. 1990. Indiana Governor's Academy Final Report. Indianapolis, IN: Indiana Department of Education.

Kuncel N. R., Hezlett S. A., \& Ones D. S. 2001. "A Comprehensive Meta-analysis of the Predictive Validity of the Graduaterecord Examinations: Implications for Graduate Student Selection and Performance." Psychological Bulletin 127:162-81. 
Li M., Monica J. T., \& Yang S. 2004. "Moral Education in Chinese Societies: Changes and Challenges." Journal of Moral Education 33 (4):405-28.

Li Z. 2014. "Shenji Lunli Panduan Nengli Nengfou Tongguo Jiaoyu Tigao - Jiyu Shenji Jioayu Guojihua Xiangmu de Shiyan Yanjiu" [Can Education Promote Moral Judgment in Ethical Audit? - An Empirical Study on an International Project]. Shenji Yanjiu [Auditing Research] 58(5):60-7.

Lin Ch.-Y. \& Ho Y.-H. 2009. "Cultural Influences on Moral Reasoning Capacities of Purchasing Managers: A Comparison Across the Taiwan Strait." Social Behavior and Personality 37 (2):203-08.

Liu H. 1995. "Lvelun Daode Xuanze Nengli de Peiyang" [On the Cultivation of Moral Choice Competence]. Jiaoyu Pinglun [Education Review] 35(4):26-27.

Loevinger J. 1976. Ego Development. San Francisco: Jossey-Bass Publishers.

Ma H.-K. 1988. "Objective Moral Judgment in Hong Kong, Mainland China, and England." Journal of Cross-Cultural Psychology, March Issue:78-95.

Ma H.-K. 1989. "Moral Orientation and Moral Judgment in Adolescents in Hong Kong, Mainland China and England." Journal of Cross-Cultural Psychology 20:152-77.

Ma H. \& Liu Er. 2017. Traditional Chinese Leisure Culture and Economic Development - A Conflict of Forces. Nature America Inc., 1 New York Plaza, New York, NY 10004, U.S.A.DOI 10.1057/978-1-137-59253-8.

Martin R. M., Shafto M., \& Van Deinse W. 1977. "The Reliability, Validity and Design of the Defining Issues Test." Developmental Psychology 13:46068.

McNeel S. 1994. "College Teaching and Student Moral Development," in J. Rest \& D. Narvaez (Eds.), Moral Development in the Professions: Psychology and Applied Ethics. Hillsdale, NJ: Erlbaum (27-50).

Narvaez D. 1993. "High Achieving Students and Moral Judgment." Journal for the Education of the Gifted 16(16):268-79.

Nisbett R. E. \& Wilson T. D. 1977. "Telling More Than We Can Know: Verbal Reports on Mental Processes." Psychological Review 84:231-59.

Nonaka I. 1994. "A Dynamic Theory of Organizational Knowledge Creation." Organization Science 5(1):14-37.

O'Flaherty J. \& Gleeson J. 2014. „Longitudinal Study of Levels of Moral Reasoning of Undergraduate Students in an Irish University: The Influence of Contextual Factors." Irish Educational Studies 33:57-74.

O'Flaherty J. \& McGarr 0. 2014. "The Use of Case-based Learning in the Development of Student Teachers' Levels of Moral Reasoning." European Journal of Teacher Education 37:312-30.

Polanyi M. 1958. Personal Knowledge. Chicago, IL: The University of Chicago Press.

Qi W. \& Tang H. 2004. "The Social and Cultural Background of Contemporary Moral Education in China." Journal of Moral Education 33 (4):465-80. 
Rest J. R. 1975. "Recent Research on an Objective Test of Moral Judgment: How the Important Issues of a Moral Dilemma are Defined," in D. DePalm \& J. M. Foley (Eds.), Moral Development: Current Theory and Research. New York: John Wiley.

Rest J. R. 1976. "New Approaches in the Assessment of Moral Judgment," in T. Lickona (Ed.), Moral Development and Behavior: Theory, Research, and Social Issues. New York: Holt, Rinehart \& Winston.

Rest J. R. 1979a. Revised Manual for the Defining Issues Test: An Objective Test of Moral Judgment Development. Unpublished manuscript, University of Minnesota, Moral Research Projects.

Rest J. R. 1979b. Development in Judging Moral Issues. Minneapolis: University of Minnesota Press.

Rest J. R. 1986. Moral Development: Advances in Research and Theory. New York: Praeger.

Rest J. R., Cooper D., Coder R., Masanz J., \& Anderson D. 1974. „Judging the Important Issues in Moral Dilemmas: An Objective Test of Development." Developmental Psychology 10:491-501.

Rest J. R. \& Narvaez D. 1998. Defining Issues Test 2. Minneapolis, MN: University of Minnesota.

Rest J. R., Narvaez D., Bebeau M. J., \& Thoma S. J. 1999. Postconventional Moral Thinking: A Neo-Kohlbergian Approach. Mahwah, NJ: Lawrence Erlbaum Associates.

Rest J. R., Narvaez D., Bebeau M. J., \& Thoma S. J. 2009. "Postconventional Moral Thinking - A Neo-Kohlbergian Approach." Psychology Press 4:56-70.

Rest J. R., Narvaez D., Thoma S. J. \& Bebeau M. J. 1999. DIT2: "Devising and Testing a Revised Instrument of Moral Judgment." Journal of Educational Psychology 91(4):644-59.

Rest J. R., Thoma S. J., \& Edwards L. 1997. "Designing and Validating a Measure of Moral Judgment: Stage Preference and Stage Consistency Approaches." Journal of Educational Psychology 89(1): 5-28.

Rest J. R., Thoma S. J., Narvaez D., \& Bebeau M. J. 1997. "Alchemy and Beyond: Indexing the Defining Issues Test." Journal of Moral Education 89(3):498-507.

Shweder R. A., Mahapatra M., \& Miller J. G. 1987. "Culture and Moral Development," in J. Stigler, R. A. Shweder, \& G. Herdt (Eds.), Cultural Psychology: Essays on Comparative Human Development. New York: Cambridge University Press (73-112).

Soares D. L., Lemos G. C., Primi R., \& Almeida L. S. 2015. "The Relationship Between Intelligence and Academic Achievement Throughout Middle School: The Role of Students' Prior Academic Performance." Learning and Individual Differences 41:73-8. 
Sun X. 2005. "Queding Wenti Ceyan de Xinlixue Yanjiu" [Psychological Research on DIT-2]. Master's thesis, retrieved from CNKI database (http://kns.cnki.net/KCMS/detail/detail.aspx?dbcode=CMFD\&dbname $=$ CMFD2007\&filename $=2007108072 . n h \& u i d=$ WEEvREcwSlJHSldRa1F hcEE0NXdo)

Thoma S. J. 2002. "An Overview of the Minnesota Approach to Research in Moral Development." Journal of Moral Education 31:225-245.

Thoma S. J. 2006. "Research Using the Defining Issues Test," in M. Killen \& J. Smetana (Eds.), Handbook of Moral Development. Hillsdale, NJ: Lawrence Erlbaum (67-91).

Thoma S. J. \& Dong Y. 2014. "The Defining Issues Test of Moral Judgment Development." Behavior Development Bulletin 19(3):55-61.

Travel China Guide. (n.d.). Available online at https://www.travelchinaguide.com/tourism/2016statistics/outbound. htm (retrieved on July 17, 2017).

Uleman J. S. \& Bargh J. A. 1989. Unintended Thought. New York: Guilford Press.

Wang Y. \& Guo B. 2011. "Dangdai Daxuesheng Daode Renzhi Yanjiu de Xinjinzhan" [Development on Moral Judgment of College Students in Modern China]. Jiaoyu Tansuo [Education Exploration] 242(8):115-17.

Wu K. 2000. "Jiaohui Xuanze: Mianxiang Ershiyi Shiji de Woguo Xuexiao Daode Jiaoyu de Biyou Zhilu" [Making Students Learn to Make a Moral Choice: The Only Way to Reform School Moral Education in 21 st Century]. In: Jie Lu \& Xiaoman Zhu (Eds.), Daode Jiaoyu Luntan [Moral Education Forum]. Nanjing: Najning Shifan Daxue Chubanshe [Nanjing Normal University Press] (92-109).

Yang S. 2006. "Queding Eenti Ceyan Yu Xin Ke'er Boge Lilun" [Defining Issue Test and Neo-Kohlbergian Theory]. Sixiang Lilun Jiaoyu [Thoughts, Theory and Education] 7:26-9.

Yang S. \& Wu H. 2004. "Queding Wenti Ceyan Yu Daode Xinli de Jiegou Chengfen Tanxi" [Defining Issues Test and Analysis of Structural Elements in Moral Psychology]. Jiaoyu Kexue [Educational Science] 20 (6):56-9.

Yang S. \& Zeng F. 2014. "Shenjishi Daode Renzhi Fazhan Shuiping yu Lunli Juece de Guanxi Yanjiu" [Relationship Between Moral Cognitive Development and Ethical Decision-Making]. Zhongguo Zhece Kuaijishi [The Chinese Certified Public Account] 78:79-84.

Zeidner M. \& Matthews G. 2000. "Intelligence and Personality," in R. Sternberg (Ed.), Handbook of Intelligence. New York: Cambridge University Press (581-610).

Zhao X. 2007. “Gongwuyuan Daode Sushi Ceping Yanjiu” [Assessment on Moral Competence of Government Officials in China]. Xiandai Shangye [Modern Business] 170:57-59. 
Zhu X. 2000. "Yude Shi Jiaoyu de Linghun, Dongqing Shi Jiaoyu de Guanjian" [Moral Education is the Core to Education, Empathy is the Core to Moral Education]. In J. Lu \& X. Zhu (Eds.), Daode Jiaoyu Iuntan [Moral Education Forum]. Nanjing: Najning Shifan Daxue Chubanshe [Nanjing Normal University Press] (16-20). 


\author{
Qian Zhang (Guangdong) \\ Stephen J. Thoma (Alabama)
}

Research on Moral Judgment Competency of College Students in Mainland China with DIT-2

\begin{abstract}
The purpose of this paper was to (1) examine moral judgment competency of a sample of 811 Chinese college students from a Southern university in mainland China with DIT-2; and (2) test whether gender, education, major, academic performance, and one-child policy have significant effect on the participants' moral judgment competency. Results show that the participants score high in both Personal Interest schema and Postconventional schema, while low in Maintaining Norms schema. Gender and major have significant effect on participants' moral judgment competency in China, while education level, academic performance and one-child family have no significant effect on their moral judgment competency. Reasons are discussed in the paper.
\end{abstract}

Keywords: DIT-2ॅॅmoral judgment competenc, college student, Chinese participants

Acknowledgments: This paper is granted by the project by National Office for Education Sciences Planning (project number: BEA180114) and the project by Guangdong Planning Office of Philosophy and Social Science (project number: GD16XJY31).

Ethics in Progress (ISSN 2084-9257). Vol. 8 (2017). No. 2, Art. \#7, pp. 80-96.

Creative Commons BY-SA 3.0

Doi: 10.14746/eip.2017.2.7 